the 15 th-Minimum 29.12 on the 9 th-monthly mean of thermometer 46.92 - of Barometer 29.641. Amount of rain 4.87 inches. Peach tree in blos. som on the 27 th.

March came in mildly and gave fine weather, with the exception of a few days, until about the time of the Equinox. Thunder storms on the 2 nd and 20th days, and another of great severity on the $23 \mathrm{rd}$, during which four buildings in this city, without conductors, were struck by the lightning. Since that time the weather has been marked by great changes. On the 30 th there were frequent storms of hail and rain with cold winds from $W$, and N. W. Much high wind during the month. Maximum of Thermometer 79 on the 18 th-Minimum 23 on the 31 st-Range 56-Maximum of Barometer 29.83 on the $21 \mathrm{st-Minimum} 29.10$ on the 16 th at 6 P. M.Range 73. Mean temperature of March 54.25-Mean of Barometer 29.453 -Rain 4.05 inches.

As you seem to have forgotten that in my observations the italic $c$ de. notes cloudy, and the roman c clear, it may not be improper to state that in the notes on the winter Solstice of 1839 , the 24 th day only presented a clear sky.

Very respectfully, yours, \&c, JAMES HaMILTON.

University of Nashville, April 1, 1840.

Meteorological Observations, at the Vernal Zquinox of 1840 , made in counformity with the instructions of the South African Literary and Philosophical Institution, at the University of Nashville, Tennessee, in North

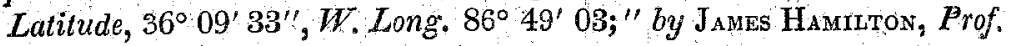
Math, and N. Philos.

March 21,1840 .

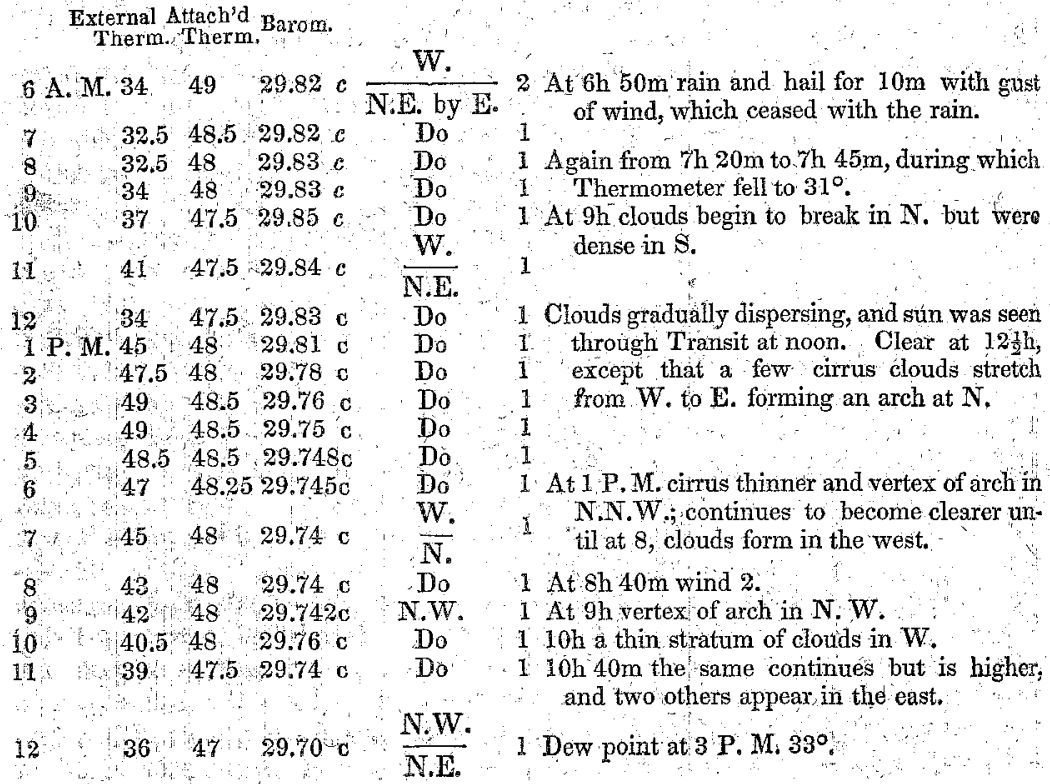


March 22.

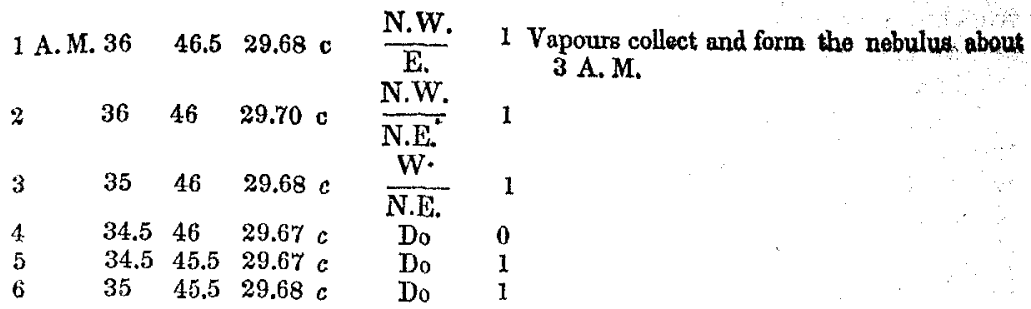

Mean time found by Transit and kept by a superior clock. Fahrenheit's Thermometer-Barometer by Dolland--diameter of tube .4 inch, cup 2 inch.; height above ground 38 feet, and 128 feet above low water of the Cumberland river. External Thermometer, 35 feet above ground, north exposure.

On the day preceding the Equinox, double currents of wind were observed, the upper from the west and the under from the east. At sunrise the Thermometer was at $51^{\circ}$ and the Barometer at 29.63. Clouds were gathering in the west and continued to become more and more dense until ten minutes past noon, at which time there was a storm of rain and hail, with thunder and lightning, that lasted until 1 P. M. When the storm began, the thermometer was at 45 and had fallen to 39 before its end. The double currents were perceptible, with the exception of a few hours, until the evening of the 23 rd when a very violent thunder storm commenced at half-past 8 P. M. and lasted until 10 P. M, at which time the N. W. wind prevailed and blew very violently till sunset on the 25 th. The clouds disappeared during the night of the 24 th.

The double currents are marked in the table with the upper above a line and the under below.

J. H.

\section{Civil Engineering.}

A Popular Exposition of the Incorrectness of the Tariffs of Toll in use on the Public Improvements of the United Slates. By Charles Eldet, Jr., Civil Engineer.

[Concluded from Page 172.]

$\oint$ 4. Of the most judicious charge on articles of heavy burden and small
value.

12. I conceive that it is essential to the fulfilment of the condition, that the tax levied on the trade of the line shall be reconcilable with principles of equity, that the charge at each point shall be proportional to the ability of the article to sustain it; and, it fortunately happens, that when the charges are regulated in the mode that will produce the maximum revenue, this condition will be fully satisfied.

We are to understand by the ability of a commodity to sustain a charge for carriage, the difference between the cost of production and the market value of the object. If the article be worth 810 in market, and it costs $\$ 6$ to produce and prepare it for market, it will sustain any charge for transportation, including both freight and toll, not exceeding 84 . But its ability to sustain a charge for toll only, depends on the position in which it reaches 